\title{
Integrated morphologic and functional assessment of the aortic root after different tissue valve root replacement procedures
}

\author{
Ryo Torii, PhD, ${ }^{\mathrm{a}, \mathrm{b}, \mathrm{c}}$ Ismail El-Hamamsy, MD, PhD, ${ }^{\mathrm{b}}$ Mohamed Donya, $\mathrm{MD},{ }^{\mathrm{d}}$ \\ Sonya V. Babu-Narayan, MB BS, BSc, PhD, MRCP, ${ }^{\mathrm{e}}$ Michael Ibrahim, MD, ${ }^{\mathrm{b}}$ Philip J. Kilner, MD, PhD, \\ Raad H. Mohiaddin, MD, PhD, FRCR, FRCP, FESC, ${ }^{\mathrm{e}} \mathrm{Xiao}$ Yun $\mathrm{Xu}, \mathrm{PhD},{ }^{\mathrm{c}}$ and \\ Magdi H. Yacoub, MD, DSc, FRCS, FRCP, FRS ${ }^{a, b}$
}

Objectives: This study was undertaken to explore aspects of the hemodynamic function of different biologic tissue aortic valve root replacements. We set out to image and display the spatiotemporal distributions of axially directed blood velocity through the aortic root.

\begin{abstract}
Methods: The flow velocities through a plane transecting the aortic root were measured by 2-dimensional cine phase-contrast magnetic resonance velocity mapping in 44 subjects: 29 patients who had undergone aortic root replacement approximately 10 years previously (13 autografts, 10 stentless xenografts, and 6 homografts) and 15 healthy control subjects. With cine as well as velocity images, aortic sinus dimensions, effective orifice area, and several velocity parameters were measured. Color-coded plots of velocity relative to the sinus cross sections and velocity-time plots were used to compare spatiotemporal distributions of velocity.
\end{abstract}

Results: Peak flow velocity was similar between the autografts $(102 \pm 28.0 \mathrm{~cm} / \mathrm{s})$ and control valves $(119 \pm 20.0$ $\mathrm{cm} / \mathrm{s})$ but was higher in xenografts $(167 \pm 36.0 \mathrm{~cm} / \mathrm{s})$ and homografts $(206 \pm 91.0 \mathrm{~cm} / \mathrm{s})$. These measurements showed an inverse relationship with the effective orifice area $(7.27 \pm 0.20,4.24 \pm 0.81,3.37 \pm 0.32$, and $3.28 \pm$ $0.87 \mathrm{~cm}^{2}$, respectively). Autograft peak flow velocity showed no significant difference from control valve peak flow velocity, despite larger root dimensions $(P<.001)$. The graphic displays provided further spatiotemporal information.

Conclusions: Peak velocities and spatiotemporal flow patterns depend on the type of valve substitute. In the parameters measured, autograft replacements differed least from normal aortic valves. (J Thorac Cardiovasc Surg 2012;143:1422-8)

A number of surgical procedures to replace the aortic root and valves are currently being used. These include valve-sparing operations, aortic homograft, xenograft, and autograft root. ${ }^{1-4}$ The influences of different types of valve operations on the size of the root and the pattern of flow in the aortic

From the Qatar Cardiovascular Research Center, ${ }^{a}$ Doha, Qatar; the Harefield Heart Science Centre, ${ }^{\mathrm{b}}$ Harefield Hospital and Imperial College London, United Kingdom; the Department of Chemical Engineering, ${ }^{\mathrm{c}}$ Imperial College London, United Kingdom; the Aswan Heart Centre, ${ }^{\mathrm{d}}$ Aswan, Egypt; and Royal Brompton Hospital and National Heart and Lung Institute, ${ }^{\mathrm{e}}$ Imperial College, London, United Kingdom.

R.T. is supported as Qatar Cardiovascular Research Center Fellow by The Qatar Foundation. S.B.-N. is supported by a British Heart Foundation Fellowship. Also supported in part by the NIHR Cardiovascular Biomedical Research Unit of Royal Brompton and Harefield NHS Foundation Trust and Imperial College London.

Disclosures: Authors have nothing to disclose with regard to commercial support.

Received for publication Sept 25, 2011; revisions received Dec 2, 2011; accepted for publication Dec 14, 2011; available ahead of print Feb 23, 2012.

Address for reprints: Magdi H. Yacoub, MD, DSc, FRCS, FRCP, FRS, Harefield

Heart Science Centre, Hill End Rd, Harefield, Middlesex UB9 6JH, United

Kingdom (E-mail: m.yacoub@imperial.ac.uk).

$0022-5223 / \$ 36.00$

Copyright (c) 2012 by The American Association for Thoracic Surgery

doi:10.1016/j.jtcvs.2011.12.034 root have not been examined in detail. Recent studies have shown that the normal aortic root and valve perform sophisticated functions ${ }^{5,6}$ that can influence patterns of blood flow in different parts of the aorta, coronary circulation, and systemic circulation, as well as influencing left ventricular function and endothelial functions of the ascending aorta and arch. $^{7,8}$ Cardiovascular magnetic resonance (CMR) imaging with phase-contrast velocity mapping allows noninvasive measurement of the spatiotemporal distribution of the components of velocity in the aortic root, ${ }^{9-11}$ which can be used in the investigation of several clinical conditions. ${ }^{12}$ The purpose of this investigation was to use this approach to characterize the spatiotemporal patterns of the flow directed through the aortic root after 3 different types of aortic root replacement and to compare these with flow conditions in healthy subjects.

\section{MATERIALS AND METHODS Study Population}

Written consent was obtained from all subjects. The study protocol was approved by the local ethics committee, and the study complied with the Declaration of Helsinki. The study group comprised 44 subjects, including 29 patients who had undergone aortic root replacement more than 10 years before imaging with either an autograft $(n=13)$, a homograft $(n=6)$, or a xenograft $(\mathrm{n}=10$; Medtronic Freestyle; Medtronic Inc, Minneapolis, 


\section{Abbreviations and Acronyms}

$\mathrm{CMR}=$ cardiovascular magnetic resonance

$\mathrm{SSFP}=$ steady-state free precision

Minn). All patients had normally functioning valves, with no significant stenosis or regurgitation according to echocardiographic assessment at the time of analysis. Fifteen healthy volunteers without previous history of cardiovascular disease or associated risk factors were studied as a control group. Relevant demographic information about the study subjects is summarized in Table 1.

\section{CMR Image Acquisition}

All patients' studies were performed on a 1.5-T Siemens Avanto magnetic resonance scanner (Siemens Medical Solutions USA, Inc, Malvern, $\mathrm{Pa}$ ) approximately 10 years after valve surgery as a part of clinical follow-up at Royal Brompton and Harefield Hospitals (London, UK). The healthy volunteers were scanned at Alfa Scan Radiology Center (Cairo, Egypt) with a Philips Achieva 3.0-T scanner (Royal Philips Electronics, Amsterdam, The Netherlands). Multislice anatomic images of the heart and great vessels were obtained with single-shot steady-state free precession (SSFP) sequence. Cine SSFP imaging in the left ventricular outflow tract from an appropriate transaxial section was then obtained, and this was followed by a left ventricular outflow tract crosscut cine acquisition. Cine SSFP was then acquired in the short-axis plane of the aortic valve positioned in the 2 left ventricular outflow tract views at midsinus level of the aortic root (Figure E1). Through-plane, breath-hold, retrospectively gated phase-contrast flow mapping was then acquired above the aortic valve at midsinus level, with care taken to avoid the valve plane, which moves during the cardiac cycle. For each subject, images (pairs of magnitude and phase images) were obtained at 20 equally distributed phases throughout the cardiac cycle with breath-holding, retrospectively electrocardiographically gated sequence. Typical matrix size was $256 \times 176$, with typical in-plane spatial resolution of $1.25 \mathrm{~mm}$ and slice thickness of $6 \mathrm{~mm}$. Phase-contrast encoding velocity ranged from 150 to $430 \mathrm{~cm} / \mathrm{s}$. Detailed imaging parameters are summarized in Table E1.

\section{Image Analysis}

Each pair of acquired images (magnitude and phase images) was first segmented to obtain through-plane velocity maps over the cross section; a magnitude image was segmented to obtain an anatomic cross section of the aortic root, and then the through-plane velocity map on the cross section was calculated with the corresponding phase image in reference to encoding velocity. Volumetric flow was then calculated by integrating the velocity map over the cross section. By temporally interpolating 20 phases through the cardiac cycle, the time-varying volumetric flow curve (waveform) was also obtained. Morphologic and hemodynamic parameters were calculated on the basis of the reconstructed flow data. The parameters included stroke volume, ejection time, temporal maximum flow rate, mean flow rate throughout the cardiac cycle, spatial maximum velocity at peak flow rate, spatial mean shear rate $\left(\sqrt{(d v / d x)^{2}+(d v / d y)^{2}}\right)$ over the cross section, cross-sectional area of the aortic sinus, and effective orifice area at peak flow rate. In addition, the diameter of the sinus (as determined from the cross-sectional area, $d=2 \sqrt{A_{\text {sinus }} / \pi}$ ) was derived from the cine SSFP images for the valve substitute groups and from phasecontrast images for healthy subjects. The parameters were compared among the subject groups, as were the velocity profiles. In this study, the effective orifice area was determined as the area in which velocities were higher than the mean velocity over the cross section. All analysis was carried out with an in-house MATLAB program (The MathWorks, Inc, Natick, Mass). An example of image data analysis is shown in Figure E2.

\section{Statistical Analysis}

Data are expressed as mean $\pm \mathrm{SD}$. Comparisons between groups of the demographic data and of the morphologic and hemodynamic parameters were carried out with the use of 1-way analysis of variance first. The morphologic and hemodynamic parameters for root substitute groups were also compared against control data with an unpaired, 2-tailed Welch $t$ test. All statistical analyses were performed with a statistics software environment $\mathrm{R}$ version 12.2 (http://www.r-project.org/).

\section{RESULTS}

Morphologic and hemodynamic parameters derived for the 4 groups are summarized in Table 2. A statistical comparison of key data is shown in Figure 1.

\section{Morphologic Parameters}

The sinus cross-sectional area and diameter were larger for the autograft group than for the control group $(P<.001)$, whereas the other 2 groups showed values comparable to those in the control group. When the ratio of

TABLE 1. Study population demographic characteristics

\begin{tabular}{|c|c|c|c|c|c|}
\hline Variable & Autograft $(n=13)$ & Xenograft $(n=10)$ & Homograft $(n=6)$ & Control $(\mathbf{n}=15)$ & $P$ value* \\
\hline Age $(y$, mean $\pm S D)$ & $42.8 \pm 8.5$ & $73.5 \pm 7.9$ & $67.3 \pm 10.8$ & $30.9 \pm 5.1$ & $<.001$ \\
\hline Sex (no. male) & $11 / 13(85 \%)$ & $6 / 10(60 \%)$ & $4 / 6(67 \%)$ & $11 / 15(73 \%)$ & .63 \\
\hline Time since operation (y, mean $\pm \mathrm{SD}$ ) & $10.3 \pm 1.1$ & $8.2 \pm 0.7$ & $7.6 \pm 0.7$ & N/A & $<.001$ \\
\hline Heart rate (beats/min, mean $\pm \mathrm{SD}$ ) & $71.6 \pm 15.7$ & $75.8 \pm 18.1$ & $67.8 \pm 19.9$ & $72.1 \pm 10.2$ & .79 \\
\hline Systolic BP $(\mathrm{mm} \mathrm{Hg}$, mean $\pm \mathrm{SD})$ & $135.5 \pm 18.0$ & $126.6 \pm 16.6$ & $130.3 \pm 11.3$ & $110.7 \pm 12.8$ & $<.001$ \\
\hline Diastolic BP $(\mathrm{mm} \mathrm{Hg}$, mean $\pm \mathrm{SD})$ & $68.3 \pm 14.4$ & $73.7 \pm 10.1$ & $76.5 \pm 3.1$ & $72.7 \pm 8.8$ & .42 \\
\hline$\triangle \mathrm{BSA}$ & $1.006 \pm 0.08 \dagger$ & $1.02 \pm 0.05$ & $1.002 \pm 0.03 \ddagger$ & - & .82 \\
\hline \multicolumn{6}{|l|}{ Indication for surgery (no.) } \\
\hline Aortic stenosis & 2 & 2 & 2 & - & \\
\hline Aortic regurgitation & 7 & 4 & 1 & - & \\
\hline Aortic stenosis and regurgitation & 4 & 3 & 1 & - & \\
\hline Structural valve abnormality & 0 & 1 & 1 & - & \\
\hline Postoperative LV mass index $\left(\mathrm{g} / \mathrm{m}^{2}\right.$, mean $\left.\pm \mathrm{SD}\right)$ & $94.7 \pm 33.0$ & $131.4 \pm 63.1$ & $120.5 \pm 36.6$ & - & .21 \\
\hline
\end{tabular}

$B P$, Blood pressure; $\triangle B S A$, ratio of body surface area (time of cardiovascular magnetic resonance scan to time of operation); $L V$, left ventricular. *Comparisons by 1 -way analysis

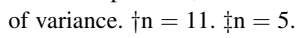


TABLE 2. Derived morphologic and hemodynamic parameters

\begin{tabular}{|c|c|c|c|c|c|}
\hline Variable & Autograft $(n=13)$ & Xenograft $(n=10)$ & Homograft $(n=6)$ & Control $(n=15)$ & $P$ value* \\
\hline $\mathrm{A}_{\text {sinus }}\left(\mathrm{cm}^{2}\right)$ & $13.6 \pm 3.71$ & $9.18 \pm 1.80$ & $7.89 \pm 1.00$ & $8.09 \pm 1.64$ & $<.001$ \\
\hline $\mathrm{d}_{\text {sinus }}(\mathrm{cm})$ & $4.12 \pm 0.56$ & $3.40 \pm 0.33$ & $3.17 \pm 0.20$ & $3.19 \pm 0.32$ & $<.001$ \\
\hline$A_{\text {orifice }}\left(\mathrm{cm}^{2}\right)$ & $7.27 \pm 0.20$ & $3.37 \pm 0.32$ & $3.28 \pm 0.87$ & $4.24 \pm 0.81$ & $<.001$ \\
\hline $\mathrm{A}_{\text {orifice }} / \mathrm{A}_{\text {sinus }}$ & $0.539 \pm 0.063$ & $0.378 \pm 0.069$ & $0.418 \pm 0.099$ & $0.527 \pm 0.035$ & $<.001$ \\
\hline Heart rate (beats/min) & $71.6 \pm 15.7$ & $75.8 \pm 18.1$ & $67.8 \pm 19.9$ & $72.1 \pm 10.2$ & .79 \\
\hline Stroke volume $(\mathrm{mL})$ & $88.6 \pm 17.5$ & $67.0 \pm 15.1$ & $81.7 \pm 22.0$ & $81.2 \pm 10.6$ & $<.05$ \\
\hline Ejection time (ms) & $331.1 \pm 41.7$ & $336.4 \pm 53.6$ & $359.1 \pm 77.7$ & $323.8 \pm 36.8$ & .55 \\
\hline $\mathrm{Q}_{\max }(\mathrm{mL} / \mathrm{s})$ & $508.7 \pm 102.8$ & $375.7 \pm 53.5$ & $424.0 \pm 115.9$ & $437.1 \pm 54.5$ & $<.01$ \\
\hline $\mathrm{Q}_{\text {mean }}(\mathrm{mL} / \mathrm{s})$ & $121.5 \pm 28.7$ & $81.2 \pm 11.5$ & $91.5 \pm 35.6$ & $97.0 \pm 14.7$ & .10 \\
\hline $\mathrm{dQ} / \mathrm{dt}\left(\mathrm{mL} / \mathrm{s}^{2}\right)$ & $3795 \pm 1775$ & $3005 \pm 1046$ & $2935 \pm 1173$ & $3684 \pm 781$ & .30 \\
\hline $\mathrm{V}_{\max }(\mathrm{cm} / \mathrm{s})$ & $102 \pm 28.0$ & $167 \pm 36.0$ & $206 \pm 91.0$ & $119 \pm 20.0$ & $<.001$ \\
\hline $\operatorname{MSR}(1 / \mathrm{s})$ & $16.4 \pm 4.1$ & $32.1 \pm 12.5$ & $32.4 \pm 10.1$ & $20.7 \pm 5.2$ & $<.001$ \\
\hline
\end{tabular}

All values are mean $\pm \mathrm{SD} . A_{\text {sinus }}$, Cross-sectional area of aortic sinus; $d_{\text {sinus }}$, diameter of aortic sinus $\left(2 \sqrt{\mathrm{A}_{\text {sinus }} / \pi}\right.$.); $A_{\text {orifice }}$, effective orifice area at peak flow rate; $Q_{\text {max }}$ temporal maximum flow rate; $Q_{\text {mean }}$, mean flow rate throughout the cardiac cycle; $V_{\text {max }}$, spatial maximum velocity at peak flow rate; $M S R$, mean shear rate. $*$ Comparisons by 1 -way analysis of variance.

orifice area to the sinus area was compared, however, both the xenograft and homograft groups showed significantly smaller values than did the healthy control group $(P<.001$ and $P<.05$, respectively) whereas the value in the autograft group was comparable to the control value.

\section{Hemodynamic Parameters}

Flow regurgitation was not observed. There were no statistically significant differences among the subject groups in heart rate and ejection time. The stroke volume and the maximum and mean flow rates for the xenograft group were significantly lower than the control values $(P<.05)$, whereas those for the autograft group were higher than those for the other groups $(P=.20$ for stroke volume, $P<.05$ and $P=.29$ for maximum and mean flow rates, respectively). The mean temporal profiles of volumetric flow rate (volumetric flow waveform) for each subject group (Figure 2, A) showed differences in flow rate; the shapes of the flow waveforms were similar, but the peak values differed. The variability of peak flow rate for healthy control subjects was found to be lower than those of the other groups; mean $\pm \mathrm{SD}$ values for autograft, xenograft, homograft, and control groups were $508 \pm 102,375 \pm$ $56.3,424 \pm 115$, and $433 \pm 54.4 \mathrm{~mL} / \mathrm{s}$, respectively. The temporal gradient of flow rate $(\mathrm{dQ} / \mathrm{dt})$ values in systole were $3795 \pm 1775,3005 \pm 1046,2935 \pm 1173$, and $3684 \pm 781 \mathrm{~mL} / \mathrm{s}^{2}$ for autograft, xenograft, homograft, and control groups, respectively. The most prominent difference was observed in maximum velocity. Relative to healthy control subjects, the xenograft group showed approximately
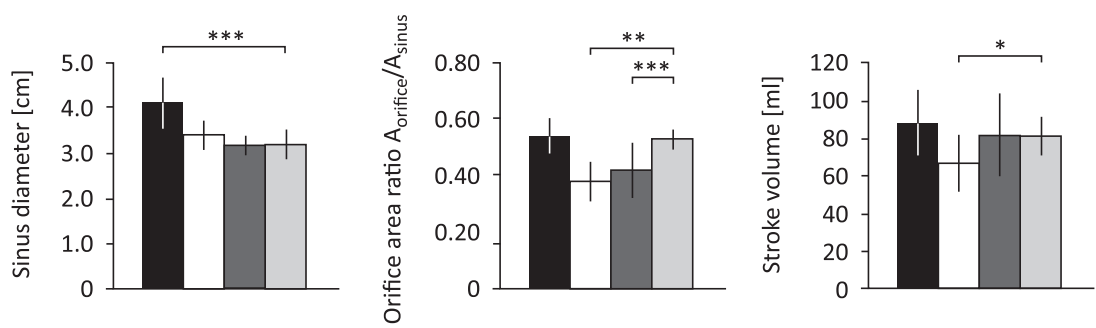

Autograft $(n=13)$

$\square$ Xenograft $(\mathrm{n}=10)$

$\square$ Homograft $(n=6)$

Normal $(n=15)$
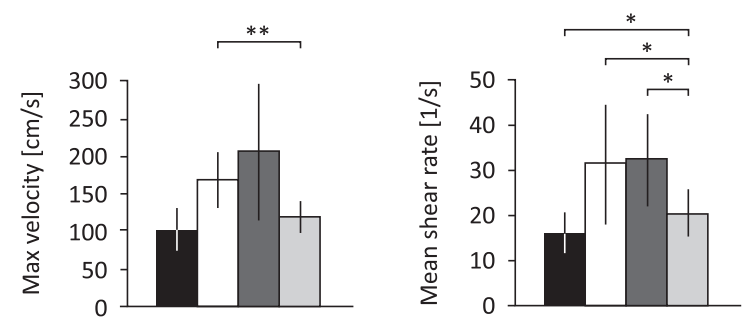

FIGURE 1. Statistical comparisons of key morphologic and hemodynamic parameters: comparisons of sinus diameter, effective orifice area ratio, stroke volume, maximum velocity, and mean shear rate among the subject groups (values mean $\pm \mathrm{SD}$ ). Asterisk indicates $P<.05$ versus control; double asterisk indicates $P<.01$ versus control; triple asterisk indicates $P<.001$ versus control. 


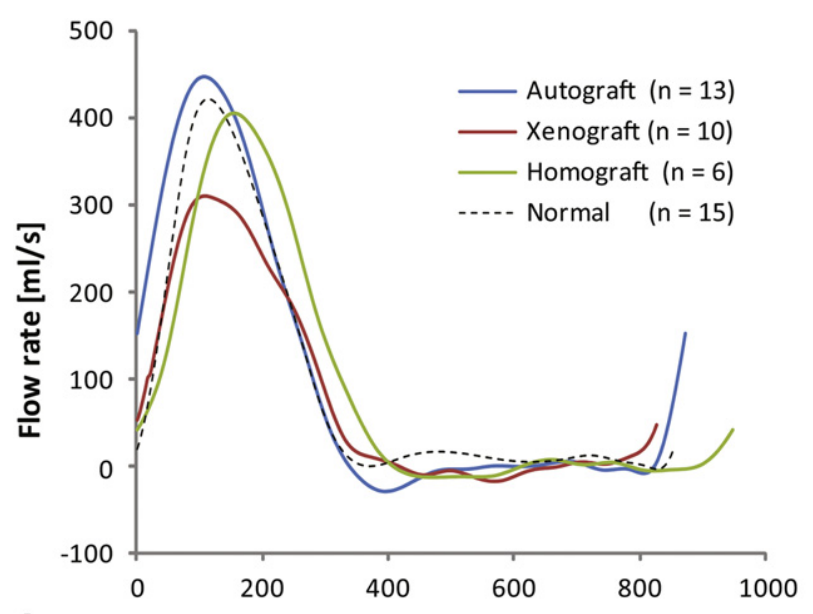

A

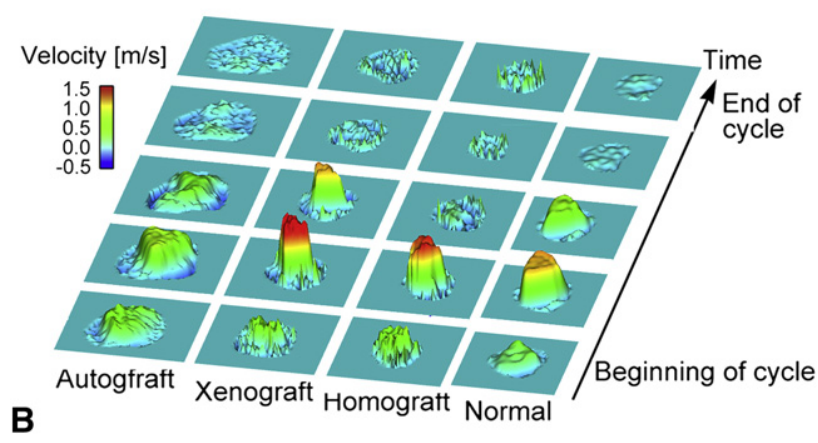

FIGURE 2. A, Volumetric flow rate waveforms. Mean reconstructed temporal volumetric flow rate profiles (waveforms) for 4 subject groups (SD at peak flow for each group, 149, 123, 98.1, and $53.7 \mathrm{~mL} / \mathrm{s}$, respectively). The individual profiles were first normalized to heart rate and averaged over the subject group, and then the mean RR interval for each group was assigned to the averaged profile. B, Spatiotemporal velocity maps. Representative spatiotemporal velocity maps for 4 groups.

1.4 times higher velocity $(P<.01)$, and the homograft group showed 1.7 times higher velocity, although the latter difference was not statistically significant $(P=.06)$.

\section{Spatiotemporal Flow Patterns}

In addition to the quantitative analysis, 5 phases form the temporal evolution of the spatial velocity profiles, with 1 representative case from each group, are displayed in Figure $2, B$. The velocity profiles distal to the valve were steeper, with higher peaks of velocity, for xenografts and homografts than for control valves. Conversely, the velocity profiles for autografts were broader, with lower peaks of velocity. A high-velocity jet was associated with a parajet shear layer, as evaluated by mean shear rate, which was significantly higher for the xenograft and homograft groups than for the control group $(32.1 \pm 12.5,32.4 \pm 10.1$, and $20.7 \pm 5.2 \mathrm{~s}^{-1}$, respectively; $P<.05$ ). In contrast, autograft mean shear rate was significantly lower than the control value $\left(16.4 \pm 4.1\right.$ vs $\left.20.7 \pm 5.2 \mathrm{~s}^{-1} ; P<.05\right)$.

\section{Shape of the Effective Orifice Area}

Shapes of the effective orifice area at peak flow were visualized as contours (broken lines) relative to color-coded velocity maps, as shown in Figure 3. As presented in Table 2, cross sections as well as effective orifice areas for the autograft group were larger than in the other 3 groups. In terms of orifice shape, those in the autograft group tended to be nearly triangular (eg, A01, A04, A06, A09, A11, A13), with vertices close to the edge of the sinus. On the other hand, the orifice shape for xenograft and homograft groups was likely to be nontriangular and the edges of the orifice to be not very close to the edge of the sinus, suggesting that the valve might not fully open.

\section{DISCUSSION}

This study has demonstrated and measured differences in the patterns of flow directed through the aortic root relative to 3 types of aortic root substitute. This finding may have important implications, because flow in the aortic root is a significant determinant of both systemic and coronary flows.

\section{Aortic Root Morphology}

The larger diameter in the autograft group than in the control group was expected from reading the literature, including our own reports. ${ }^{13}$ For example, our current observation $(4.12 \pm 0.56 \mathrm{~cm})$ agrees with the aortic root diameter measured with CMR at the sinus level ${ }^{14}$ (mean, $4.52 \mathrm{~cm}$; range, $3.47-5.75 \mathrm{~cm}$ ) and with an echocardiographic observation $^{13}(3.756 \pm 0.48 \mathrm{~cm}$, nearly constant for 4 years after surgery). Diameters for the other groups are all comparable to reported normal values, for example, $3.23 \pm 0.39 \mathrm{~cm}$ measured with multislice computed tomography. ${ }^{15} \mathrm{Al}-$ though late dilatation is a major concern with pulmonary autografts, our current result did not show clear signs of excessive clinically relevant dilatation even 10 years after surgery. Indeed, in our large clinical cohort of patients undergoing the Ross procedure, no acute aortic events were observed during a long study period. ${ }^{4}$ The high effective orifice area to sinus cross-sectional area ratio may indicate that the autograft opens as freely as does a normal valve, whereas the lower area ratios for the other valve substitutes suggest restricted valve opening despite globally unaffected hemodynamic function. This difference is also illustrated by the effective orifice area visualization in Figure 3; autograft orifice morphology was more likely to be triangular (eg, A01, A04, A06, A09, A11, and A13), which simulates the orifice shape of the trileaflet valve, as seen in control subjects (N01, N03, N05, N10, N11, N14, and N15) but not in subjects with other valve substitutes. A sudden expansion downstream of an orifice with small effective area has been associated with energy loss in the 

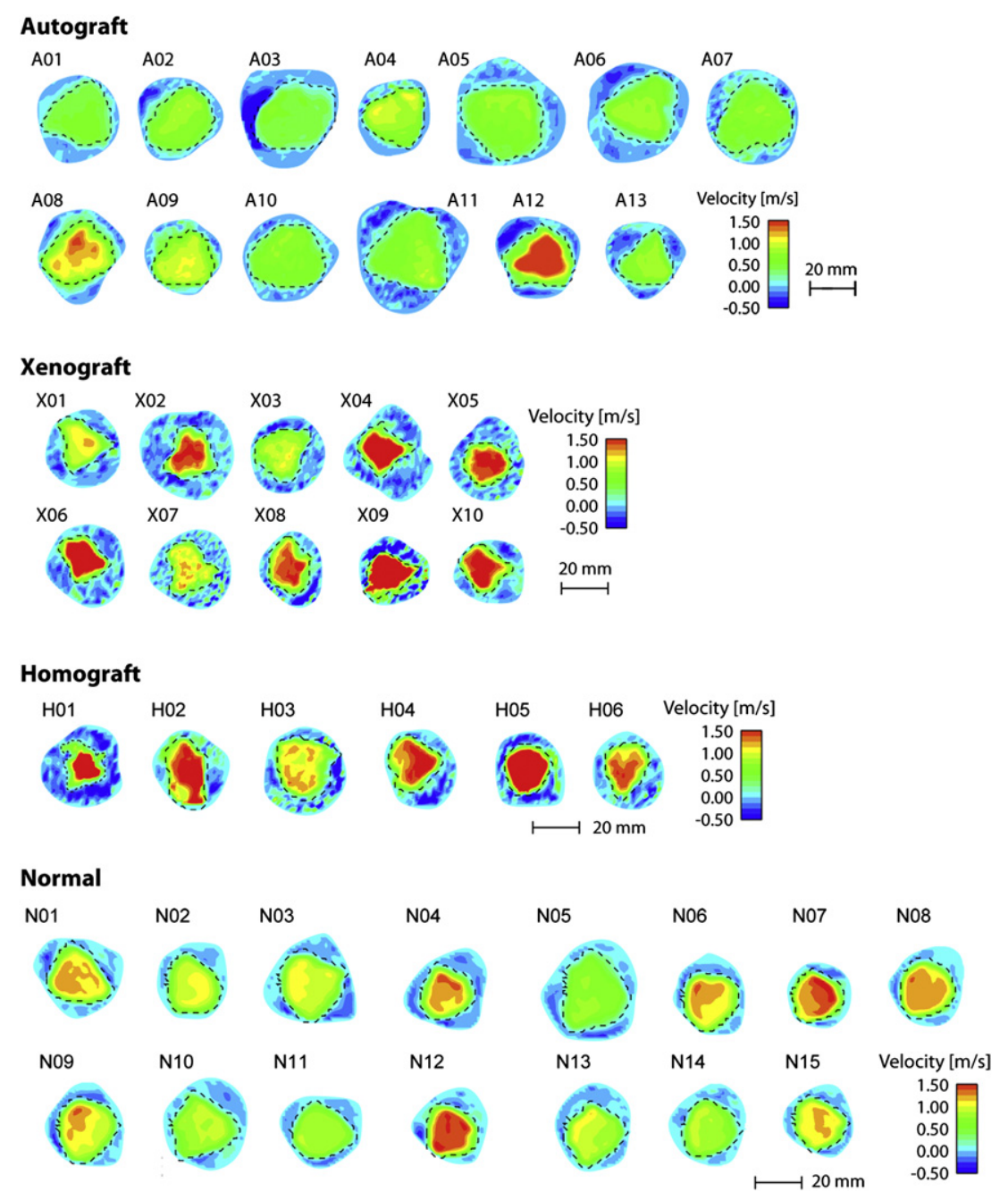

FIGURE 3. Effective orifice area. Velocity maps (color contours) and effective orifice areas (broken lines) visualized on cross sections above the valves at peak flow for all 4 subject groups.

flow field ${ }^{16,17}$ and has been shown to be relevant to left ventricular dysfunction in extreme cases. ${ }^{18}$

Aortic root morphology and effective orifice area have been investigated mainly with echocardiograms. For example, Wang and colleagues ${ }^{19}$ reported that the effective orifice area of the pulmonary autograft was larger than that of the homograft. Our CMR-based technique, which has been successfully applied to the assessment of mitral and pulmonary valve regurgitation, ${ }^{20}$ provides both qualitative and quantitative assessment of the effective orifice. Further, by integrating with flow velocity information obtained from phase-contrast CMR, this approach enables the comprehensive assessment of aortic valve functions, which has been shown effective in correlating aortic wall elasticity, aortic dilatation, and severity of aortic regurgitation and left ventricular hypertrophy. ${ }^{21}$ In this study, there was tendency toward lower echocardiographically derived left ventricular mass after autograft replacement $\left(94.7 \pm 33 \mathrm{~g} / \mathrm{m}^{2}\right)$ than after xenograft $\left(131.5 \pm 63 \mathrm{~g} / \mathrm{m}^{2}\right)$ or homograft $(120.5 \pm$ $\left.36 \mathrm{~g} / \mathrm{m}^{2}\right)$ replacement $(P=.12$ vs xenografts and $P=.18$ vs homografts). This is almost certainly the result of the observed larger effective orifice area of the autograft, and it may explain the survival advantage previously reported in a randomized trial comparing autografts with homograft root replacements. ${ }^{4}$

\section{Hemodynamic Parameters and Flow Patterns Through the Valve}

The hemodynamic parameters showed that xenografts tended to result in higher maximum velocity values than those seen in healthy control subjects $(P<.05)$. The same trend was also observed for homografts, although the later trend was not statistically significant. Conversely, results of the autograft group showed lower maximum velocity. This difference was strongly linked to the effective orifice area; that is, a small orifice produced a high-velocity jet 
into the root, because the stroke volumes were similar among autograft, homograft, and control groups. Among the patients with xenografts, higher maximum velocity than the control value was found even with a lower stroke volume, because of the small orifice area. A high-speed jet through the valve would yield a higher shear rate in the aortic flow, which could be associated with increased energy dissipation in the aorta. This is due to increased turbulence and associated high Reynolds stress. ${ }^{22}$ Our results showed higher mean shear rate over the sinus crosssection for patients with xenografts and homografts than for control subjects, whereas that for the autograft group was lower. This suggests a lower turbulence level in the aorta for autografts, which is consistent with the findings of Steinbrüchel and colleagues, ${ }^{22}$ who showed low turbulence level in autografts relative to mechanical valves. Although the effect of flow instability or turbulence in the cardiovascular system is still not fully understood, it has been shown in aortic aneurysms that flow instabilities affect endothelial shear stress. ${ }^{23}$ Among other hemodynamic parameters, systolic temporal gradient of flow rate $(\mathrm{dQ} / \mathrm{dt})$ showed low values for the xenografts and homografts relative to control values, whereas the autografts maintained the systolic increase of flow rate at the same level as in the control subjects, although the difference was not statistically significant. The low shear rate for pulmonary autografts indicates that the spatiotemporal gradients of flow through the autograft were gradual, even more so than in the control subjects; however, the ejection (ie, systolic increase of the flow rate) was at the same level as in the control subjects, as shown by the high $\mathrm{dQ} / \mathrm{dt}$. On the other hand, flows through xenografts and homografts were more rapid, with a higher-velocity jet than seen in the control subjects. A high-velocity jet through the valve tends to impact strongly on the aortic wall. ${ }^{11}$ This typically causes focally high endothelial shear stress, as demonstrated by a computational fluid dynamics study of an aorta with hypothetical model of aortic valves, which showed a strong impact of the jet through a bicuspid valve on the ascending aortic wall, causing high endothelial shear stress. ${ }^{24}$

Our results clearly show that the velocity profile through the aortic valve depends strongly on the type of valve substitute. The difference in ascending aortic flow patterns as a result of type of root substitute would affect endothelial shear stress patterns on the aortic wall and thus could result in different aortic wall structure and function through shear stress-driven tissue adaptation. ${ }^{8}$ The elucidation of more detailed in vivo ascending aortic flow patterns, with medical image-based computational fluid dynamics ${ }^{25}$ or 4-dimensional magnetic resonance imaging, ${ }^{26}$ would add more insight to our findings. This study lays the groundwork for detailed investigation on the aortic blood flow patterns in relation to midterm to long-term surgical outcomes, which have a significant clinical relevance. The superior hemodynamic and flow characteristics of the autograft reported here could explain, at least in part, its enhanced survival and quality of life relative to homograft in a recently reported prospective, randomized trial. $^{4}$

\section{Limitations}

One limitation is the measurement of the through-plane component of velocity only. This represents the principal directional component, however, and its measurement leaned itself to graphic display and comparison of spatiotemporal distributions of velocity between groups and between individuals within groups. Another limitation of this study is the differences in age among the subject groups. The healthy control group was young $(31.4 \pm 5.1$ years old), whereas xenograft and homograft groups were older (76.5 \pm 7.5 and $71.0 \pm 11.0$ years old, respectively), and the autograft group was in the middle ( $46.8 \pm 9.4$ years old). Although it would have been desirable to have an agematched comparison, the effect of the age difference is unlikely to be significant in this study in light of the insignificant differences in cardiac function characteristics (heart rate, stroke volume, and ejection time), apart from systolic blood pressure which might have interfered the interpretation of the result. Likewise, variability in sex and other clinical parameters, such as medication, is a limitation. CMR acquisition and resulting flow mapping can be more accurate with an acquisition sequence enabling the acquisition plane after the valve motion during the cardiac cycle. ${ }^{27} \mathrm{Be}-$ cause of this valve motion artifact, sampling frequency, and spatial resolution, our CMR measurement was judged to be insufficient to allow performance of dynamic distensibility measurement, which is our interest in a future study. These studies represent the findings at rest at a single point in time (around 10 years postoperatively), and no preoperative studies had been performed for comparison. Further studies over a longer period, and particularly studies during exercise, are warranted.

\section{CONCLUSIONS}

Through-plane magnetic resonance velocity mapping and quantitative postprocessing as a noninvasive functional assessment tool was applied to patients who had undergone different root replacement procedures. The results showed that the type of valve substitute is an important factor affecting spatiotemporal distribution of flow through the aortic root. Among the investigated valve substitute groups (autograft, xenograft, and homograft), autograft valves differed least from normal aortic valves in terms of maximum velocity, despite the larger sinus dimension, whereas the velocity profiles through xenograft and homograft valves showed narrower, higher-velocity forward flow regions. The discrepancy between different valve substitute groups showed an inverse relationship with the ratio of effective orifice area to sinus area. The results demonstrated the potential value 
of image-based flow characterization, and this modality could help determine the roles of biomechanics in longterm outcome after aortic replacement procedures.

\section{References}

1. El-Hamamsy I, Clark L, Stevens LM, Sarang Z, Melina G, Takkenberg JJ, et al. Late outcomes following freestyle versus homograft aortic root replacement: results from a prospective randomized trial. J Am Coll Cardiol. 2010;55:368-76.

2. Elefteriades JA. Should we abandon homografts? J Am Coll Cardiol. 2010;55: 377-8.

3. Wilhelmi MH, Bara C, Kofidis T, Wilhelmi M, Pichlmaier M, Haverich A. Longterm cardiac allograft valves after heart transplant are functionally and structurally preserved, in contrast to homografts and bioprostheses. J Heart Valve Dis. 2006;15:777-82.

4. El-Hamamsy I, Eryigit Z, Stevens L, Sarang Z, George R, Clark L, et al. Longterm outcomes after autograft versus homograft aortic root replacement in adults with aortic valve disease: a randomised controlled trial. Lancet. 2010;376: 524-31.

5. Higashidate M, Tamiya K, Beppu T, Imai Y. Regulation of the aortic valve opening: In vivo dynamic measurement of aortic valve orifice area. $J$ Thorac Cardiovasc Surg. 1995;110:496-503.

6. Yacoub MH, Kilner PJ, Birks EJ, Misfeld M. The aortic outflow and root: a tale of dynamism and crosstalk. Ann Thorac Surg. 1999;68(3 Suppl):S37-43.

7. Davies JE, Parker KH, Francis DP, Hughes AD, Mayet J. What is the role of the aorta in directing coronary blood flow? Heart. 2008;94:1545-7.

8. El-Hamamsy I, Yacoub MH. Cellular and molecular mechanisms of thoracic aortic aneurysms. Nat Rev Cardiol. 2009;6:771-86.

9. Kilner PJ, Yang GZ, Mohiaddin RH, Firmin DN, Longmore DB. Helical and retrograde secondary flow patterns in the aortic arch studied by three-directional magnetic resonance velocity mapping. Circulation. 1993;88:2235-47.

10. Barker AJ, Lanning C, Shandas R. Quantification of hemodynamic wall shear stress in patients with bicuspid aortic valve using phase-contrast MRI. Ann Biomed Eng. 2010;38:788-800.

11. Liu X, Weale P, Reiter G, Kino A, Dill K, Gleason T, et al. Breathhold timeresolved three-directional MR velocity mapping of aortic flow in patients after aortic valve-sparing surgery. J Magn Reson Imaging. 2009;29:569-75.

12. Torii R, Xu XY, El-Hamamsy I, Mohiaddin R, Yacoub MH. Computational biomechanics of the aortic root. Aswan Heart Centre Sci Pract Series [serial online]. 2011 Dec 30;2:16. Available from: http://www.qscience.com/doi/pdf/10.5339/ ahcsps.2011.16.

13. Carr-White GS, Afoke A, Birks EJ, Hughes S, O'Halloran A, Glennen S, et al. Aortic root characteristics of human pulmonary autografts. Circulation. 2000; 102(19 Suppl. 3):III15-21.
14. Hokken RB, de Bruin HG, Taams MA, Schiks-Berghou M, Steyerberg EW, Bogers AJ, et al. A comparison of adult pulmonary autograft diameter measurements with echocardiography and magnetic resonance imaging. Eur Heart J. 1998;19:301-9.

15. Tops LF, Wood DA, Delgado V, Schuijf JD, Mayo JR, Pasupati S, et al. Noninvasive evaluation of the aortic root with multislice computed tomography. JACC Cardiovasc Imaging. 2008;1:321-30.

16. Garcia D, Pibarot P, Dumesnil JG, Sakr F, Durand LG. Assessment of aortic valve stenosis severity: a new index based on the energy loss concept. Circulation. 2000;101:765-71.

17. Pibarot P, Dumesnil JG. Prosthesis-patient mismatch. Aswan Heart Centre Sci Pract Series [serial online]. 2011 Apr 14;1:7. Available from: http://www. qscience.com/doi/pdf/10.5339/ahcsps.2011.7.

18. Briand M, Dumesnil JG, Kadem L, Tongue AG, Rieu R, Garcia D, et al. Reduced systemic arterial compliance impacts significantly on left ventricular afterload and function in aortic stenosis. J Am Coll Cardiol. 2005;46:291-8.

19. Wang A, Jaggers J, Ungerleider RM, Lim CS, Ryan T. Exercise echocardiographic comparison of pulmonary autograft and aortic homograft replacements for aortic valve disease in adults. J Heart Valve Dis. 2003;12:202-8.

20. Chan KM, Wage R, Symmonds K, Rahman-Haley S, Mohiaddin RH, Firmin DN, et al. Towards comprehensive assessment of mitral regurgitation using cardiovascular magnetic resonance. J Cardiovasc Magn Reson. 2008;10:61.

21. Grotenhuis HB, Ottenkamp J, Westenberg JJ, Bax JJ, Kroft LJ, de Roos A. Reduced aortic elasticity and dilatation are associated with aortic regurgitation and left ventricular hypertrophy in nonstenotic bicuspid aortic valve patients. J Am Coll Cardiol. 2007;49:1660-5.

22. Steinbrüchel DA, Hasenkam JM, Nygaard H, Riis CM, Sievers HH. Blood velocity patterns after aortic valve replacement with a pulmonary autograft. Eur J Cardiothorac Surg. 1997;12:873-5.

23. Giddens DP, Mabon RF, Cassanova RA. Measurements of disordered flows distal to subtotal vascular stenoses in the thoracic aortas of dogs. Circ Res. 1976;39:112-9.

24. Viscardi F, Vergara C, Antiga L, Merelli S, Veneziani A, Puppini G, et al. Comparative finite element model analysis of ascending aortic flow in bicuspid and tricuspid aortic valve. Artif Organs. 2010;34:1114-20.

25. Tan FP, Torii R, Borghi A, Mohiaddin RH, Wood NB, Xu XY. Fluid-structure interaction analysis of wall stress and flow patterns in a thoracic aortic aneurysm. Int J Appl Mech. 2009;1:179-99.

26. Markl M, Harloff A, Bley TA, Zaitsev M, Jung B, Weigang E, et al. Time-resolved 3D MR velocity mapping at 3T: improved navigator-gated assessment of vascular anatomy and blood flow. J Magn Reson Imaging. 2007;25:824-31.

27. Roes SD, Hammer S, van der Geest RJ, Marsan NA, Bax JJ, Lamb HJ, et al. Flow assessment through four heart valves simultaneously using 3-dimensional 3-directional velocity-encoded magnetic resonance imaging with retrospective valve tracking in healthy volunteers and patients with valvular regurgitation. Invest Radiol. 2009;44:669-75. 


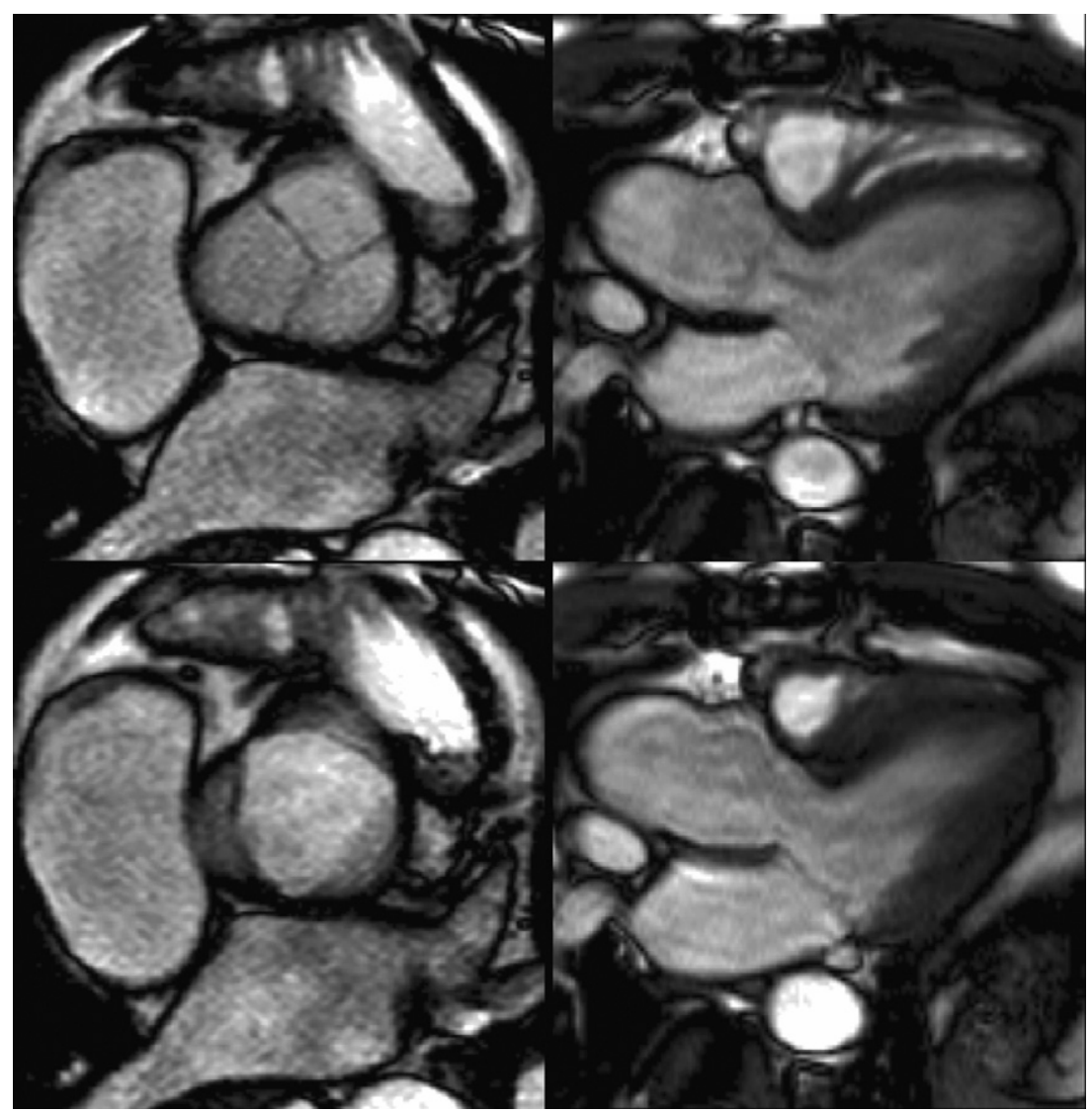

FIGURE E1. Selected frames from cine steady-state free precession images. Images acquired from an autograft patient at beginning of systole (top) and peak flow (bottom); a cross-sectional view of the aortic sinus at the valve (left) and a long-axis view of the left ventricular outflow tract (right). 


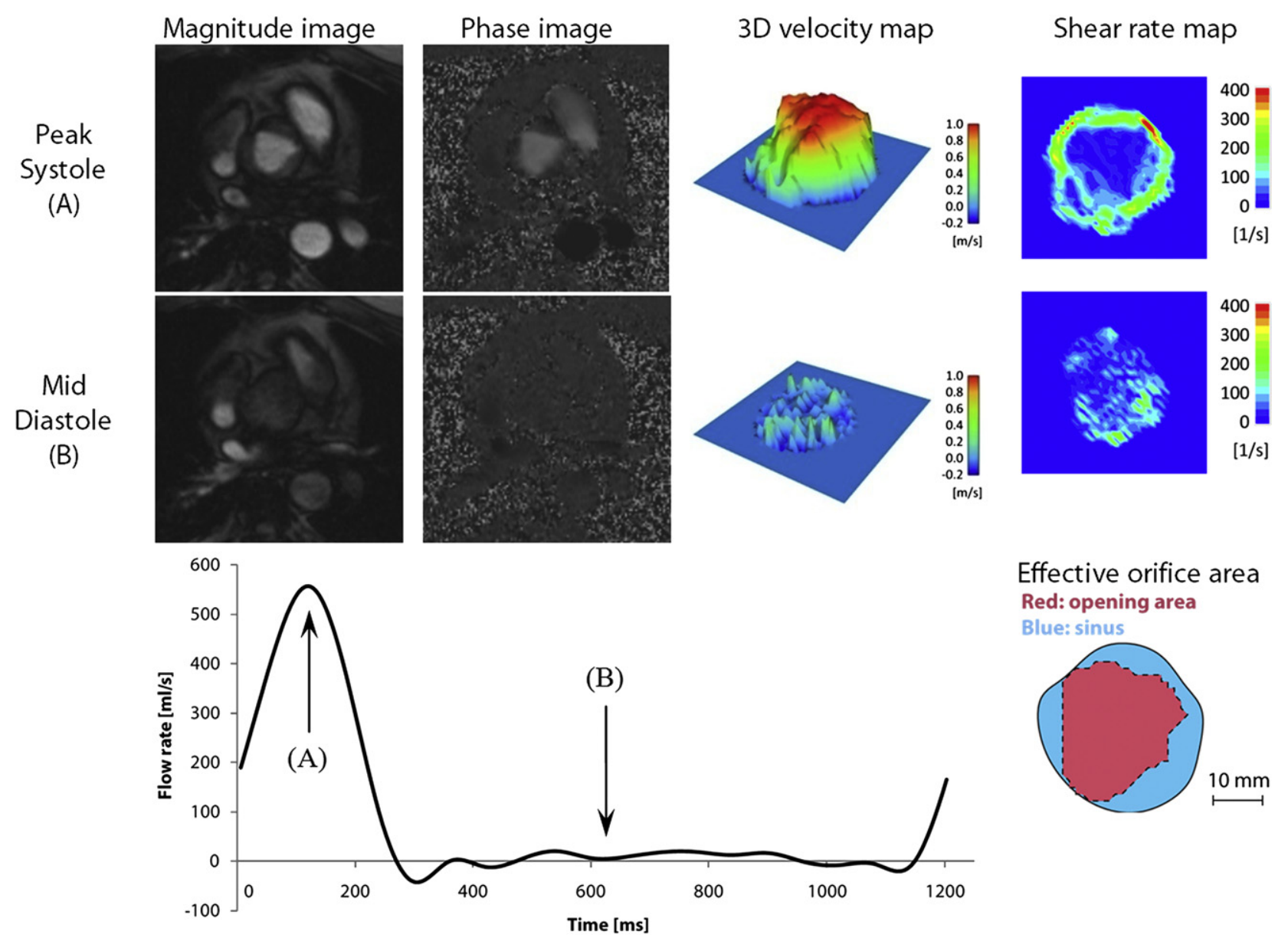

FIGURE E2. Typical image analysis result for a patient with an autograft. Original magnitude and phase magnetic resonance images, reconstructed velocity profile in 3-dimensional representation, and shear rate map (from left to right in the top row) at peak $(A)$ and at middiastole $(B)$. The bottom row shows the reconstructed flow waveform and the calculated effective orifice area.

TABLE E1. Imaging parameters

\begin{tabular}{lcc}
\hline \multicolumn{1}{c}{ Site } & $\begin{array}{c}\text { Royal Brompton and } \\
\text { Harefield Hospital }\end{array}$ & $\begin{array}{c}\text { Alfa Scan Radiology } \\
\text { Center }\end{array}$ \\
\hline Scanner & Siemens Avanto 1.5 T & Philips Achieva 3.0 T \\
Echo time (ms) & 3.9 & 3 \\
Repetition time (ms) & 75 & 5 \\
Flip angle & $30^{\circ}$ & $10^{\circ}$ \\
Slice thickness (mm) & 6 & 8 \\
Typical matrix size & $256 \times 176$ & $256 \times 256$ \\
Typical spatial resolution $(\mathrm{mm} /$ pixel) & 1.25 \\
$\quad$ x & 1.25 & 1.25 \\
y & 1.25 & - \\
Encoding velocity (cm/s) & & - \\
Autograft & $150-200$ & - \\
Xenograft & $150-400$ & 200 \\
Homograft & $150-430$ & \\
Normal valve & - & \\
\hline
\end{tabular}

